\title{
Evaluation of hypertension related knowledge, attitudes and practices at community level in Kabul
}

\begin{abstract}
Background: Evaluation of knowledge, attitudes, and practices plays key role in hypertension control. Since little data is available from Kabul, Afghanistan, hence this study was planned to generate scientific data about it.

Methods: A cross-sectional, descriptive, questionnaire based survey was designed to cover the study participants from general public of Kabul City. A 30 item pretested questionnaire was served to collect the data.

Results: A total of 201 out of 384 adult individuals of either gender volunteered to participate in the survey of which $>61 \%$ were women. Out of all interviewed individuals 33 had the history of hypertension of which $24(72.2 \%)$ of them were women. Significant association $(\mathrm{p}=0.036)$ was observed between gender and high blood pressure. The majority of hypertensive respondents were aged $>45$ years, where significance $(\mathrm{p}=0.017)$ was found between age and high blood pressure. More than half of the hypertensive population was jobless at the time of survey and nearly $46 \%$ had a positive family history of hypertension. Overall, the hypertension related knowledge among respondents was found to be adequate. Positive attitudes and appropriate practices were found to be existed during the analysis. Interestingly $98.5 \%$ of the interviewed participants believed that daily exercise had a beneficial role in hypertension control. About $65 \%$ participants knew the correct value of normal blood pressure $(120 / 80 \mathrm{mmHg})$.
\end{abstract}

Conclusion: Sufficient awareness should be created among the public, public health authorities, medical practitioners, and pharmacists to inform, educate, and inform the public comprehensively about hypertension and its associated consequences.
Volume 7 Issue 3 - 2019

\section{Mohammad Bashaar,' Fahad Saleem, ${ }^{2}$ Vijay \\ Thawani, ${ }^{3}$ Mohamed Azmi Hassali, ${ }^{4}$ Tafseera Hashemi ${ }^{5}$}

'Health Policy Analyst, SMART Afghan International Trainings \& Consultancy, Afghanistan

${ }^{2}$ Faculty of Pharmacy and Health Sciences, University of Baluchistan, Pakistan

3Professor of Pharmacology, People's College of Medical Sciences \& Research Centre, India

${ }^{4}$ Professor of Social and Administrative Pharmacy, School of Pharmaceutical Sciences, Universiti Sains Malaysia, Malaysia

${ }^{5}$ Faculty of Biology, Kabul University, Afghanistan

Correspondence: Mohammad Bashaar, Health Policy Analyst, SMART Afghan International Trainings \& Consultancy, Shahri Naw, District 4, Kabul,Afghanistan, Email mbashaar@gmail.com

Received: April 24, 2019 | Published: May 08, 2019
Abbreviations: WHO, world health organization; IEC, information, education and communication; HBP, high blood pressure; $\mathrm{NCD}$, non-communicable diseases; MOPH, ministry of public health; BPHS, basic package of health services; EPHS, essential package of hospital services; KAP, knowledge, attitudes and practices

\section{Introduction}

The high blood pressure (HBP), a chronic circulatory disease, is one of the most widespread non-communicable diseases (NCD) globally. More than 360,000 deaths in US in 2013 occurred due to HBP. ${ }^{1}$ The HBP is preventable, but mismanagement leads to serious medical complications, e.g., heart failure, coronary vascular disease, encephalopathy, acute renal failure and intracranial or subarachnoid hemorrhage. ${ }^{2}$ According to World Health Statistics 2017, an estimated 17.7 million deaths occurred due to cardiovascular disease, accounting for $45 \%$ of all NCD deaths. ${ }^{3}$ Unfortunately, the incidence of hypertension, a key tracer indicator of health services for cardiovascular diseases, has not declined in many low-income countries since 2000. ${ }^{3}$ In Afghanistan the NCDs have ranked low in government and donor prioritization. There has not been any national policy, strategy, targets or coordinating body for NCDs so far. The national NCDs surveillance system, which is crucial for informed policy and focused strategy, is yet to be established, and currently the surveillance for NCDs is limited. ${ }^{4}$ The Ministry of Public Health (MOPH) considers the integration of NCDs such as prevention and control of cardiovascular diseases, diabetes, and chronic pulmonary diseases in the Basic Package of Health Services (BPHS) and Essential Package of Hospital Services (EPHS). Capacity building of service providers about prevention, diagnosis and treatment of NCDs and modification of the infrastructure is needed for improving NCD management. ${ }^{4}$
The prevalence and associated complications of HBP are multi factorial like positive family history, presence of obesity, misdiagnosis, and inappropriate or insufficient therapy. In addition, HBP is associated and influenced by many genetic, hormonal, metabolic, neurological and psychological factors. The HBP is also influenced by rapid urbanization, changes in socioeconomic conditions such as sedentary life, alcohol consumption, excessive salt intake and increased stress and this burden is likely to grow in the coming decades. ${ }^{5}$ Epidemiologically, HBP is widespread globally, even in the economically developed nations such as United States where it was second most important fatality cause after tobacco. ${ }^{1}$ The HBP is one of the leading attributable risk factors for mortality in South Asia. The latest prevalence of HBP was found to be in Bangladesh: $17.9 \%$; Bhutan: 23.9\%; India: 31.4\%; Maldives: 31.5\%; Nepal: 33.8\%; Pakistan: 25\%; and Sri Lanka: 20.9\%. ${ }^{6}$

Afghanistan is equally at risk of HBP and has similar risk factors alike other populations ${ }^{7}$ and approximately half of the adult (46\%) population in Kabul city had HBP. ${ }^{8}$ Findings in 2012 from Herat, Afghanistan, Regional Hospital showed that 305 cases (113 men and 192 women) of hypertensive emergencies were registered with an average age of 49 years. ${ }^{9}$ The most important factors which play role in the prevalence of HBP are the lack of knowledge, negative attitudes and malpractices. Therefore, KAP surveys have been widely used in public health since the 1960 s as a research tool ${ }^{10}$ to evaluate the health related KAP. ${ }^{11}$ The KAP survey is useful in context of Afghanistan where population level health information and health literacy remains low and unquantified. ${ }^{12}$ Beside lack of health related knowledge, the individual attitudes and other cultural factors affect healthcare seeking behavior. ${ }^{12}$ Moreover, hypertension related knowledge and practice plays a significant role in controlling HBP and in preventing its long-term complications and co-morbidity. ${ }^{13}$ With this reasoning, 
to generate useful scientific data, a KAP survey was conducted. This paper aimed to improve the knowledge about HBP prevention, and devise feasible health education program to help the strategies in control of the HBP.

\section{Methodology}

\section{Study design and setting}

This was a cross sectional, descriptive, questionnaire based survey conducted in Kabul City of Afghanistan during 2018.

\section{Study sample and method}

Kabul city has 22 districts. This study was undertaken in district 10 which had estimated population of 355939 in $2017-18 .{ }^{14}$ For sample size calculation Raosoft calculator was used ${ }^{15}$ with confidence level of $95 \%$ and a margin of error $6.93 \%$, and our sample size was calculated to be 384 participants. To approach the participants we employed convenient sampling method. Demographic data such as age, gender and education level were obtained to record details about the current KAP towards hypertension.

\section{Data collection instruments}

To check the respondent's KAP towards HBP, a structured questionnaire was prepared in consultation with the clinicians. Literature and other validated questionnaires ${ }^{11,16-25}$ were reviewed and accommodated to suit our study setting. For face and content validity the questionnaire was reviewed by subject and language experts.

The data collection instrument had dichotomous and multi-response questions. First part consisted of seven questions about demographic data (gender, age, marital status, educational level, employment status, personal history and family history of hypertension) while the second part consisted of questions about KAP about knowledge (5 questions), attitude (7 questions), and practice (5 questions). The questionnaire was checked for internal consistency and value of Cronbach's $\alpha$ was 0.74.The questionnaire was forward translated from English into Dari (the common vernacular spoken language in the study setting) and then back-translated into English by independent translator, who had no prior knowledge of the original content. The data was collected with the questionnaire where both English and Dari languages were used. The team of data collectors was trained in the field.

\section{Ethics approval}

The study was approved by institutional review board of University of Baluchistan. The likely participants were briefed about the study and given participant information sheet in local language. The participant questions about the study were answered by the investigators. Those individuals, who consented to participate in the study, filled the questionnaire. Those needing assistance in responding to the questions were provided a neutral assistant.

\section{Statistical analysis}

Data analysis was done using SPSS version 24, using both descriptive and inferential statistics (Cross tabulation, Pearson Chi Square test of independence). The $\mathrm{P} \leq\lceil .05$ was considered to be statistically significant.

\section{Results}

After reviewing the data sheets, respondents with complete and valid data were found to be 201 out of 384 individuals with a response rate of $>50 \%$, which included $61 \%$ women. One hundred and two participants were aged between 18 to 25 years. More than $34 \%$ and $50 \%$ of the respondents were $12^{\text {th }}$ grade and university graduates respectively. Most of the interviewees $(50.7 \%)$ were jobless at the time of the survey and more than $25 \%$ were employed. Among the 201 respondents, $33(16.4 \%)$ had history of hypertension while the rest $(83.6 \%)$ mentioned that they did not have high blood pressure (Table 1).

Table I Demographic profile of respondents

\begin{tabular}{|c|c|c|c|}
\hline \multirow[t]{2}{*}{ Variables } & & \multicolumn{2}{|c|}{ Frequency } \\
\hline & & $\mathrm{n}=$ & $\%$ \\
\hline \multirow{2}{*}{ Gender } & Men & 78 & -38.8 \\
\hline & Women & 123 & -61.2 \\
\hline \multirow{4}{*}{ Age } & $18-25$ & 102 & -50.7 \\
\hline & $26-35$ & 27 & -13.4 \\
\hline & $36-45$ & 33 & -16.4 \\
\hline & $>45$ & 39 & -19.4 \\
\hline \multirow{2}{*}{ Marital Status } & Single & 102 & -50.7 \\
\hline & Married & 99 & -49.3 \\
\hline \multirow{4}{*}{ Educational level } & Illiterate & 9 & -4.5 \\
\hline & Primary & 21 & -10.4 \\
\hline & 12 Grade* & 69 & -34.3 \\
\hline & University & 102 & -50.7 \\
\hline \multirow{3}{*}{ Employment status } & Employee & 51 & -25.4 \\
\hline & Self-employed & 45 & -22.4 \\
\hline & Jobless & 102 & -50.7 \\
\hline \multirow{2}{*}{ History of hypertension } & Yes & 33 & -16.4 \\
\hline & No & 168 & -83.6 \\
\hline
\end{tabular}

*12 Grade (Higher Secondary)

Table 2 shows the analysis of bio-demographic and social factors of respondents (hypertensive and non-hypertensive). Among all respondents, $n=33$ had the history of hypertension of which $n=24$ $(72.2 \%)$ of them were women. Therefore, when the relationship between gender and hypertension was checked using Pearson Chi Square, significant relationship $(\mathrm{p}=0.036)$ was observed between the two. The majority $(\mathrm{n}=18)$ of hypertensive respondents were $>45$ years age group. Age and elevated blood pressure had a statistically significant relation $(\mathrm{p}=0.017)$. It has been stated that the people from older age group are more prone to hypertension than younger populations.

Table 3 shows that approximately 195 (65\%) knew the correct normal values for blood pressure measurement. $57.7 \%$ reported that normal top blood pressure level (systolic) is $120 \mathrm{mmHg}$ and the normal bottom blood pressure level (diastolic) is $80 \mathrm{mmHg}$. In addition, relationship between "personal history of hypertension"(hypertensive 
and non-hypertensive)" and "do you know hypertension is a disease?" was measured by applying Chi Square test of Independence and the results were statistically significant $(\mathrm{p}=.000)$. The knowledge of predisposing factors causing hypertension was found to be higher both among hypertensive's and non-hypertensive respondents. Participants were allowed to select more than one option during the interview. For example; $n=141$ and $n=138$ participants selected the factors overweight/ obesity and diet rich in salt as causes for HBP. Similarly, smoking (25.4\%), lack of physical activity (32.8\%), stress $(44.8 \%)$ and family history of HBP (40.3\%) were also indicated as important factors in raising the blood pressure. When asked about the symptoms of hypertension, "headache" was selected mostly (153 times) by the participants. One hundred and ninety eight (98.5\%) of all respondents (hypertensive and non-hypertensive) believed that exercise had a beneficial role in hypertension control.

Table 4 shows results of attitude of hypertensive's and normal respondents. Overall attitudes of all respondents (both hypertensive and normal) towards causes of HBP were positive. For example, all hypertensive respondents agreed that in order to control HBP one should consume plenty of vegetables and fruits; have regular BP checking; and visit physician regularly. In contrast, when we asked their opinion that antihypertensive should be taken to a clinic every day, it was observed that less than half of the hypertensive's and normal respondents $(n=12)$ and $(n=60)$ did not agree with the statement. All of the respondents $(n=165)$ unanimously agreed that HBP can cause heart diseases, such as heart attack, if left untreated.

Table 2 Analysis of bio-demographic and social factors of respondents $(n=201)$

\begin{tabular}{|c|c|c|c|c|c|c|c|}
\hline \multirow{2}{*}{\multicolumn{2}{|c|}{ Demographic characteristics }} & \multicolumn{3}{|c|}{ Frequency n (\%) } & \multicolumn{3}{|c|}{ Pearson Chi- Square } \\
\hline & & \multirow{2}{*}{$\begin{array}{l}\text { Hypertensive } \\
9(27.3)\end{array}$} & \multirow{2}{*}{$\begin{array}{l}\begin{array}{l}\text { Non- } \\
\text { hypertensive }\end{array} \\
69(4 I .1)\end{array}$} & \multirow{2}{*}{$\begin{array}{l}\text { Total } \\
78(38.8)\end{array}$} & \multirow{2}{*}{$\begin{array}{l}\text { Value } \\
6.643 a\end{array}$} & \multirow{2}{*}{$\begin{array}{l}\text { df } \\
2\end{array}$} & \multirow{2}{*}{$\begin{array}{l}\begin{array}{l}\text { Two-tailed } \\
\text { significance }\end{array} \\
0.036\end{array}$} \\
\hline & Men & & & & & & \\
\hline & Women & $24(72.2)$ & 99 & 123 & & & \\
\hline \multirow{4}{*}{ Age } & $18-25$ & $3(9.1)$ & 99 (58.9) & $102(50.7)$ & $15.518 \mathrm{a}$ & 6 & 0.017 \\
\hline & $26-35$ & $3(9.1)$ & $24(14.3)$ & $27(13.4)$ & & & \\
\hline & $36-45$ & $9(27.3)$ & $24(14.3)$ & $33(16.4)$ & & & \\
\hline & $>45$ & $18(54.5)$ & $21(12.5)$ & $39(19.4)$ & & & \\
\hline \multirow{4}{*}{ Education } & Illiterate & $3(9.1)$ & $6(3.6)$ & $9(4.5)$ & $\mathrm{II} .83 \mathrm{Ia}$ & 6 & 0.066 \\
\hline & Primary & $3(9.1)$ & $18(10.7)$ & $21(10.4)$ & & & \\
\hline & 12 Grade & $15(45.5)$ & $54(32.1)$ & $69(34.3)$ & & & \\
\hline & University & $12(36.4)$ & $90(53.6)$ & $102(50.7)$ & & & \\
\hline \multirow{3}{*}{ Employment Status } & Employee & $9(27.3)$ & $42(25.5)$ & $5 I(25.8)$ & $.466 \mathrm{a}$ & 2 & 0.792 \\
\hline & Self-employed & $6(18.2)$ & $39(23.6)$ & $45(22.7)$ & & & \\
\hline & Jobless & $18(54.5)$ & 84 (50.9) & $102(5 \mid .5)$ & & & \\
\hline \multirow{2}{*}{\multicolumn{2}{|c|}{$\begin{array}{l}\text { Do you have any close relative who is/was } \\
\text { suffering from hypertension? }\end{array}$}} & $15(45.5)$ & $93(55.4)$ & 108 (53.7) & $\mathrm{I} .088 \mathrm{a}$ & I & 0.297 \\
\hline & & $18(54.5)$ & $75(44.6)$ & $93(46.3)$ & & & \\
\hline \multirow{6}{*}{$\begin{array}{l}\text { If the answer is "Yes" who is } \\
\text { this person? }\end{array}$} & Father & $3(14.3)$ & $15(15.6)$ & $18(15.4)$ & $9.230 \mathrm{a}$ & 5 & 0.1 \\
\hline & Mother & $9(42.3)$ & $33(34.4)$ & $42(35.9)$ & & & \\
\hline & Father's sibling & $3(14.3)$ & $27(28.1)$ & $30(25.6)$ & & & \\
\hline & Father's parents & $0(0)$ & $6(6.2)$ & $6(5.1)$ & & & \\
\hline & Mother's parents & $0(0)$ & $6(6.2)$ & $6(5.1)$ & & & \\
\hline & Mother's sibling & $6(28.6)$ & $9(9.4)$ & $15(12.8)$ & & & \\
\hline
\end{tabular}

Table 3 Knowledge of high blood pressure among respondents

\begin{tabular}{|c|c|c|c|c|}
\hline \multirow{2}{*}{ Statements } & & \multicolumn{3}{|l|}{ Response Rate } \\
\hline & & Hypertensive & Normotensive & Total \\
\hline \multirow{3}{*}{ Do you know hypertension is a disease? } & Yes & 30 & 165 & 195 \\
\hline & No & 3 & 0 & 3 \\
\hline & Don't Know & 0 & 3 & 3 \\
\hline \multirow{3}{*}{ What is the normal level of blood pressure? } & Correct & 12 & 57 & 69 \\
\hline & Incorrect & 9 & 60 & 69 \\
\hline & Don't Know & 12 & 51 & 63 \\
\hline
\end{tabular}


Table Continued

\begin{tabular}{|c|c|c|c|c|}
\hline \multirow{2}{*}{ Statements } & & \multicolumn{3}{|l|}{ Response Rate } \\
\hline & & Hypertensive & Normotensive & Total \\
\hline \multirow{7}{*}{ What are the causes of high blood pressure? } & Diet rich in salt & 18 & 120 & 138 \\
\hline & Smoking & 3 & 48 & 51 \\
\hline & Being overweight or obese & 21 & 120 & $14 \mid$ \\
\hline & Lack of physical activity & 18 & 48 & 66 \\
\hline & Stress & 18 & 72 & 90 \\
\hline & $\begin{array}{l}\text { Family history of high blood } \\
\text { pressure }\end{array}$ & 18 & 63 & 81 \\
\hline & Chronic kidney disease & 9 & 36 & 45 \\
\hline \multirow{4}{*}{ What are the symptoms of hypertension? } & Headache & 27 & 126 & 153 \\
\hline & Restlessness/ palpitation & 18 & 87 & 105 \\
\hline & Internal heat & 12 & 69 & 81 \\
\hline & Dyspnea & 15 & 63 & 78 \\
\hline
\end{tabular}

Table 4 Attitudes towards predictors of hypertension among respondents

\begin{tabular}{|c|c|c|c|c|}
\hline \multirow{2}{*}{ Statements } & & \multicolumn{3}{|l|}{ Frequency } \\
\hline & & Hypertensive & Non-hypertensive & Total \\
\hline \multirow{3}{*}{ Should we reduce salt intake to prevent hypertension? } & Yes & 30 & 159 & 189 \\
\hline & No & 3 & 9 & 12 \\
\hline & Don't Know & 0 & 0 & 0 \\
\hline \multirow{3}{*}{ Should we use plenty of vegetables and fruits? } & Yes & 33 & 165 & 198 \\
\hline & No & 0 & 3 & 3 \\
\hline & Don't Know & 0 & 0 & 0 \\
\hline \multirow{3}{*}{ Should we lose our weight? } & Yes & 30 & 162 & 192 \\
\hline & No & 3 & 6 & 9 \\
\hline & Don't Know & 0 & 0 & 0 \\
\hline \multirow{3}{*}{$\begin{array}{l}\text { Do you think regular checking of blood pressure is } \\
\text { important? }\end{array}$} & Yes & 33 & 168 & 201 \\
\hline & No & 0 & 0 & 0 \\
\hline & Don't Know & 0 & 0 & 0 \\
\hline \multirow{3}{*}{ Should we visit physician regularly? } & Yes & 33 & 159 & 192 \\
\hline & No & 0 & 6 & 6 \\
\hline & Don't Know & 0 & 3 & 3 \\
\hline \multirow{3}{*}{$\begin{array}{l}\text { Do you think drugs for increased blood pressure must be } \\
\text { taken every day? }\end{array}$} & Yes & 12 & 60 & 72 \\
\hline & No & 15 & 84 & 99 \\
\hline & Don't Know & 6 & 24 & 30 \\
\hline \multirow{3}{*}{$\begin{array}{l}\text { Do you think increased blood pressure can cause heart } \\
\text { diseases, such as heart attack, if left untreated? }\end{array}$} & Yes & 33 & 132 & 165 \\
\hline & No & 0 & 9 & 9 \\
\hline & Don't Know & 0 & 27 & 27 \\
\hline
\end{tabular}

Results show that most of the respondents $(n=153)$ said that they check their blood pressure, when they fell ill. 75 of the respondents mentioned they visited a doctor a year ago for BP checkup and treatment. Even the normal respondents went to doctor for checking their blood pressure. Interestingly of the 33 hypertensive participants, 24 consumed their medicines on regular basis. More than half of the participants reported that they did exercise regularly (Table 5).
On comparison of the knowledge and practice of respondents about physical exercise in hypertension, we observed that among $n=198$ who believed that that exercise has beneficial role in hypertension; more than $62 \%$ were doing regular exercise. This shows that the knowledge and practice of respondents had a significant relationship $(\mathrm{p}=0.028)$ (Table 6). 
Table 5 Practices towards hypertension

\begin{tabular}{|c|c|c|c|c|}
\hline \multirow{3}{*}{ Statements } & & \multicolumn{3}{|l|}{ Frequency } \\
\hline & & \multirow{2}{*}{$\begin{array}{l}\text { Hypertensive } \\
\text { Yes }\end{array}$} & \multicolumn{2}{|c|}{ Non-hypertensive } \\
\hline & & & No & Total \\
\hline \multirow{4}{*}{ How often do you check your Blood Pressure } & Daily & 6 & 3 & 9 \\
\hline & Weekly & 3 & 24 & 27 \\
\hline & Monthly & 0 & 12 & 12 \\
\hline & When feel ill & 24 & 129 & 153 \\
\hline \multirow{3}{*}{$\begin{array}{l}\text { When was your last visit to physician for treating } \\
\text { hypertension? }\end{array}$} & Last Week & 12 & 24 & 36 \\
\hline & Last Month & 12 & 36 & 48 \\
\hline & Last Year & 9 & 66 & 75 \\
\hline \multirow{2}{*}{$\begin{array}{l}\text { Are you currently taking medication prescribed by } \\
\text { a doctor to lower your Blood Pressure? }\end{array}$} & Yes & 24 & 6 & 30 \\
\hline & No & 9 & 120 & 129 \\
\hline \multirow{2}{*}{ Do you use low salt diet for hypertension control? } & Yes & 33 & 24 & 57 \\
\hline & No & 0 & 102 & 102 \\
\hline \multirow{2}{*}{ Do you exercise regular on daily basis? } & Yes & 21 & 102 & 123 \\
\hline & No & 12 & 66 & 78 \\
\hline
\end{tabular}

Table 6 Relationship between high blood pressure knowledge and practice

\begin{tabular}{|c|c|c|c|c|c|c|}
\hline \multirow{3}{*}{$\begin{array}{l}\text { Is exercise having beneficial role in } \\
\text { hypertension? }\end{array}$} & \multicolumn{2}{|c|}{ Do you exercise regular on daily basis? } & \multirow[t]{2}{*}{ Total } & \multicolumn{3}{|c|}{ Pearson Chi-Square } \\
\hline & Yes & No & & Value & df & Asymp. Sig. (2-sided) \\
\hline & $123(62.1 \%)$ & 75 (37.9\%) & 198 & $4.802 a$ & I & 0.028 \\
\hline
\end{tabular}

\section{Discussion}

This KAP survey was aimed to know the existing HBP knowledge, attitudes and practices among respondents to pave the way for utilization of this data in advocacy and further research. Results suggest that overall general KAP towards HBP was adequate. However merely increased knowledge and positive attitudes shouldn't be perceived as a solution. Clinical management and thorough evaluation such as personal history, physical examination and selective testing of the patient is necessary. ${ }^{26}$ In order to correctly segregate the normotensive from hypertensive, it is important to use both ambulatory blood pressure and clinic measured blood pressure for confirming the diagnosis of hypertension. ${ }^{27}$

Our study results show that among all respondents more than $16 \%$ had history of hypertension, while in a study a conducted in Jalalabad City, Afghanistan, the prevalence of HBP was found to be $28.4 \%$ among 1,180 respondents. $^{28}$ In our study among all hypertensive respondents $(n=33)$ majority were women, and on analysis a significant relationship $(\mathrm{p}=0.036)$ was observed between gender and HBP. In contrast, analysis of Jalalabad City study showed significant association between HBP and gender in which women were two times more likely to be affected by HBP than men. ${ }^{28}$ According to our findings, the respondents' knowledge of predisposing factors of hypertension was high. Others ${ }^{13,29,30}$ have also reported high knowledge of hypertension. For example; more than half of the respondents felt that that overweight and diet rich in salt are the causative factors for HBP. According to WHO (2017 world health report) the leading reasons for the development of NCD (HBP) are high salt intake, inadequate intake of fruits and vegetables, overweight or obesity, lack of physical inactivity, tobacco use, high stress and high cholesterol. Our respondents were knowledgeable about these as more than $70 \%$ agreed that lack of physical activity and sedentary life are the causes for HBP.

Research reveals that life style modification is an important determinant of our physical health and an effective tool for successful treatment and control of HBP. ${ }^{31,32}$ Looking into the role of exercise, majority of interviewees believed that exercise has a beneficial role in hypertension control. Our findings are strongly supported by other studies and empirical evidence exists that exercise and physical activity play an important role in the non-pharmacological and a medicine free management and prevention of hypertension..$^{20,33-39}$ Our observation was consistent with the findings of study from Gandhinagar, India which found that $98 \%$ of the respondents knew that hypertension was a disease. Similarly the HBP related knowledge among Gandhinagar, and Kabul respondents was equal. This shows that knowledge related to HBP is sufficient among public with less understanding of their condition and regular measurement of BP. Further improvement in imparting HBP related knowledge is needed for better and improved sustainable health outcomes. Greater awareness and educational interventions are required, since research has found significant increase about hypertension awareness among the interventional group following completion of the intervention. ${ }^{40}$

In regard to respondents' attitude towards HBP, this survey found that majority of the respondents, both normal and hypertensive, had 
positive attitudes towards predictors of HBP. All the respondents agreed that consumption of vegetables and fruits, regular BP check up and consultation with physician can help in controlling HBP. More than half of the respondents felt that HBP can cause heart diseases, such as heart attack and heart failure, if not treated properly. This fact is supported by empirical research that HBP is a major factor in the cardiovascular morbidity and mortality. ${ }^{2,41,42}$ Consumption of extra table salt, in addition to what has already been included in the dish is associated with HBP and stroke and this has been proved by clinical studies. ${ }^{43,44}$ In our study, patients' practice was evaluated, where one 153 respondents said that they checked their blood pressure when they fell ill. Majority of the hypertensive's consumed their medicines regularly, which is supported by another study where more than half of the patients agreed that taking antihypertensive medicines is a lifelong necessity. ${ }^{11}$ Interestingly, all hypertensive's agreed that they were using low salt diet for hypertension control.

Our findings are consistent with Aubert et al.," study, where physical activity and exercise were found to be important factors in hypertension management. Previous study showed that sedentary life is associated with risk of hypertension. Research has shown that lifestyle modification has a significant role in control HBP. ${ }^{45}$ Our study suggests that in order to further improve the KAP about HBP and to minimize its risks, the healthcare needs to take concrete steps. ${ }^{46}$ Television and radio spots should be used for mass communication of messages about hypertension control, since mass media campaign has significant role in increasing public awareness of hypertension. ${ }^{47}$ Research shows that patients with more awareness had a positive attitude than patients with less awareness. ${ }^{46}$

\section{Limitations}

The limitation of this study was its setting in a small community. While our results are promising, we recommended a large survey to broadly portray the current situation and suggest possible ways for lasting improvements in blood pressure control and awareness. An overrepresentation of women occurred in our survey because of convenient sampling method used by us, as women showed more willingness and interest to participate in the study.

\section{Conclusion}

Our results suggest existence of greater awareness about HBP among the public. Opportunities exist for improving the information, education and communication (IEC) about HBP in healthcare. The public health authorities, medical practitioners, and pharmacists need to further educate the public comprehensively on hypertension.

\section{Ethics approval and consent to participate}

Informed, consent was obtained from all the respondents before the start of the survey. The Ethical Approval was received from University of Baluchistan.

\section{Consent for publication}

Not applicable.

\section{Availability of data and material}

All data generated or analyzed during this study are included in this published article. However, the datasets of the current study available from the corresponding author on reasonable request.

\section{Acknowledgments}

None.

\section{Competing interests}

There is no competing interest (financially and non-financially) that is associated to this manuscript. This research received no specific grant from any funding agency in the public, commercial or not-forprofit sectors.

\section{Authors' contributions}

MB: Carried out the study design and execution of the research work and writing of the initial draft of the manuscript. FS, VT and MAH: Writing and expert review of the manuscript. And TH: Reviewed the statistical analysis for appropriate writing of the manuscript and expert review of the manuscript. All authors read and approved the final version of the manuscript.

\section{References}

1. Mozaffarian D, Benjamin EJ, Go AS, et al. Heart disease and stroke statistics-2015 update: a report from the American Heart Association. Circulation. 2015;131(4):e29-e322.

2. Charles N, Shweta B. Hypertension: Hypertension crisis (Hypertension, hypertensive emergencies, hypertensive urgency, malignant hypertension). Renal \& Urology News; 2018.

3. Monitoring health for the SDGs. World Health Statistics; 2017. 116 p.

4. MOPH: National Strategy for Prevention and Control of Noncommunicable diseases (NCDs) 2013-2018. Edited by Department $\mathrm{NPaC} ; 2014$.

5. Dore G, Nagpal T. Urban transition in Mongolia: pursuing sustainability in a unique environment. Environment: Science and Policy for Sustainable Development. 2006;48(6):10-24.

6. Neupane D, McLachlan CS, Sharma R, et al. Prevalence of hypertension in member countries of South Asian Association for Regional Cooperation (SAARC): systematic review and meta-analysis. Medicine. 2014;93(13): 74 .

7. Saeed KMI, Rasooly MH, Brown NJ. Prevalence and predictors of adult hypertension in Kabul, Afghanistan. BMC Public Health. 2014;14:386.

8. Saeed KMI. Prevalence of risk factors for non-communicable diseases in the adult population of urban areas in Kabul City, Afghanistan. Cent Asian J Glob Health. 2014;2(2):69.

9. Faqiryar M. Management of emergent hypertension in Herat Regional Hospital, Afghanistan. Journal of Cardiothoracic Surgery. 2013, 8(Suppl 1):O253.

10. Newell SA, Girgis A, Sanson-Fisher RW, et al. The accuracy of selfreported health behaviors and risk factors relating to cancer and cardiovascular disease in the general population 1: A critical review. $\mathrm{Am}$ J Prev Med. 1999;17(3):211-229.

11. Aubert L, Bovet P, Gervasoni JP, et al. Knowledge, attitudes, and practices on hypertension in a country in epidemiological transition. Hypertension. 1998;31(5):1136-1145.

12. Harsch S. Health literacy in crisis-affected Afghanistan: a quantitative study on beliefs and barriers: Stefanie Harsch. European Journal of Public Health. 2017;27(suppl_3).

13. Malik A, Yoshida Y, Erkin T, et al. Hypertension-related knowledge, practice and drug adherence among inpatients of a hospital in Samarkand, Uzbekistan. Nagoya J Med Sci. 2014;76(3-4):255-263. 
14. Central Statistics Organization; Afghanistan.

15. Sample size calculator. Raosoft; 2004.

16. Pick W, Steyn K. Hypertension in family practice. A study of knowledge, attitudes and practices. S Afr Med J. 1992;82(4):257-259.

17. AI-Dharrab SA, Mangoud AM, Mohsen MFA. Knowledge, attitude and practice (KAP) of primary health care physicians and nurses towards hypertension: A study from Dammam, Saudi Arabia. J Family \& Community Med. 1996;3(2):57-63.

18. Oliveria SA, Chen RS, McCarthy BD, et al. Hypertension knowledge, awareness, and attitudes in a hypertensive population. J Gen Intern Med. 2005;20(3):219-225.

19. Shaikh MA, Dur-e-Yakta S, Kumar R. Hypertension knowledge, attitude and practice in adult hypertensive patients at LUMHS. J Liaquat Uni Med Health Sci. 2012;11(2):113-116.

20. Awotidebe T, Adedoyin R, Rasaq W, et al. Knowledge, attitude and Practice of Exercise for blood pressure control: A cross-sectional survey. Journal of Exercise Science and Physiotherapy. 2014;10(1):1-10.

21. Parmar P, Rathod GB, Rathod S, et al. Study of knowledge, attitude and practice of general population of Gandhinagar towards hypertension. International Journal of Current Microbiology and Applied Sciences. 2014;3(8):680-685.

22. Bhatia S, Khanka B, Singh D, et al. Study of knowledge, attitude and practice of general population of Lucknow towards hypertension. WJPPS. 2015;4:10.

23. Patil VN, Sangeeta D, Sagar K, et al. Survey of knowledge and awareness in patients of hypertension and survey of information that patients receive from physician for hypertension in a tertiary care hospital. WJPP. 2015;4(12):980-991.

24. Shrestha S, Adhikari B, Poudel RS, et al. Knowledge, Attitude and Practice on Hypertension Among Antihypertensive Medication Users. JNMA J Nepal Med Assoc. 2016;55(204):86-92.

25. Bollampally M, Chandershekhar P, Kumar KP, et al. Assessment of patient's knowledge, attitude and practice regarding hypertension. International Journal of Research in Medical Sciences. 2017;4(8):3299-3304.

26. Weber MA, Schiffrin EL, White WB, et al. Clinical practice guidelines for the management of hypertension in the community. J Clin Hypertens. 2014;16(1):14-26.

27. Krause T, Lovibond K, Caulfield M, et al. Management of hypertension: summary of NICE guidance. BMJ. 2011;343:d4891.

28. Saeed KMI. Prevalence of hypertension and associated factors in Jalalabad City, Nangarhar Province, Afghanistan. Cent Asian J Glob Health. 2015;4(1):134

29. Sarafidis PA, Li S, Chen SC, et al. Hypertension awareness, treatment, and control in chronic kidney disease. Am J Med. 2008;121(4):332-340.

30. Muntner P, Anderson A, Charleston J, et al. Hypertension awareness, treatment, and control in adults with CKD: results from the Chronic Renal Insufficiency Cohort (CRIC) Study. Am J Kidney Dis. 2010;55(3):441-451.
31. Chobanian AV, Bakris GL, Black HR, et al. The seventh report of the joint national committee on prevention, detection, evaluation, and treatment of high blood pressure: the JNC 7 report. JAMA. 2003;289(19):2560-2571.

32. He FJ, Markandu ND, MacGregor GA. Modest salt reduction lowers blood pressure in isolated systolic hypertension and combined hypertension. Hypertension. 2005;46(1):66-70.

33. League WH. Physical exercise in the management of hypertension Bulletin of the World Health Organization. 1991;69(2):149-153.

34. Papademetriou V, Kokkinos PF. The role of exercise in the control of hypertension and cardiovascular risk. Curr Opin Nephrol Hypertens. 1996;5(5):459-462.

35. Rippe JM, Hess S. The role of physical activity in the prevention and management of obesity. J Am Diet Assoc. 1998;98(10 Suppl 2):S31-S38.

36. Hagberg JM, Park JJ, Brown MD. The role of exercise training in the treatment of hypertension. Sports Med. 2000;30(3):193-206.

37. Diaz KM, Shimbo D. Physical activity and the prevention of hypertension. Curr Hypertens Rep. 2013;15(6):659-668.

38. Fiuza-Luces C, Garatachea N, Berger NA, et al. Exercise is the real polypill. Physiology. 2013;28(5):330-358.

39. Legido-Quigley H, Lopez PAC, Balabanova D, et al. Patients' knowledge, attitudes, behaviour and health care experiences on the prevention, detection, management and control of hypertension in Colombia: a qualitative study. PLoS One. 2015;10(4):e0122112.

40. Saleem F, Hassali MA, Shafie AA, et al. Pharmacist intervention in improving hypertension $\square$ related knowledge, treatment medication adherence and health $\square$ related quality of life: a non $\square$ clinical randomized controlled trial. Health Expect. 2015;18(5):1270-1281.

41. Kannel WB. Blood pressure as a cardiovascular risk factor: prevention and treatment. JAMA. 1996;275(20):1571-1576.

42. Landsberg L, Aronne LJ, Beilin LJ, et al. Obesity $\square$ related hypertension: Pathogenesis, cardiovascular risk, and treatment-A position paper of the Obesity Society and the American Society of Hypertension. J Clin Hypertens. 2013;15(1):14-33.

43. Perry I, Beevers D. Salt intake and stroke: a possible direct effect. $J$ Human Hypertens. 1992;6(1):23-25.

44. Chen J, Delaney K, Kwiecien J, et al. The effects of dietary sodium on hypertension and stroke development in female stroke-prone spontaneously hypertensive rats. Exp Mol Pathol. 1997;64(3):173-183.

45. Mattila R. Effectiveness of a multidisciplinary lifestyle intervention on hypertension, cardiovascular risk factors and musculoskeletal symptoms. University of Kuopio; 2009. 94 p.

46. Sabouhi F, Babaee S, Naji H, et al. Knowledge, awareness, attitudes and practice about hypertension in hypertensive patients referring to public health care centers in Khoor \& Biabanak. Iranian Journal of Nursing and Midwifery Research. 2011;16(1):34-40.

47. Oto MA, Ergene O, Tokgozoglu L, et al. Impact of a mass media campaign to increase public awareness of hypertension. Turk Kardiyol Dern Ars. 2011;39(5):355-364. 